\title{
The relationship between pain intensity and severity and depression in older people: exploratory study
}

\author{
Steve Iliffe ${ }^{* 1}$, Kalpa Kharicha ${ }^{1}$, Claudia Carmaciu ${ }^{1}$, Danielle Harari², \\ Cameron Swift ${ }^{3}$, Gerhard Gillman ${ }^{4}$ and Andreas E Stuck ${ }^{5}$
}

Address: ${ }^{1}$ Department of Primary Care \& Population Sciences, University College London, London, UK, ${ }^{2}$ Department of Ageing \& Health, St Thomas' Hospital, London, UK, ${ }^{3}$ Kings College London, Clinical Age Research Unit, Kings College Hospital, London, UK, ${ }^{4}$ Institute of Social \& Preventive Medicine, University of Bern, Bern, Switzerland and ${ }^{5}$ University Department of Geriatrics, Spital Bern-Ziegler and University of Bern Hospital, Bern, Switzerland

Email: Steve Iliffe* - s.iliffe@pcps.ucl.ac.uk; Kalpa Kharicha - k.kharicha@pcps.ucl.ac.uk; Claudia Carmaciu - c.carmaciu@ucl.ac.uk; Danielle Harari - danielle.harari@kcl.ac.uk; Cameron Swift - cameron.swift@kcl.ac.uk; Gerhard Gillman - gillmann@ispm.unibe.ch; Andreas E Stuck - andreas.stuck@spitalnetzbern.ch

* Corresponding author

Published: 28 July 2009

BMC Family Practice 2009, 10:54 doi:10.1 I86/147|-2296-10-54
Received: 16 April 2009

Accepted: 28 July 2009

This article is available from: http://www.biomedcentral.com/I47I-2296/10/54

(c) 2009 lliffe et al; licensee BioMed Central Ltd.

This is an Open Access article distributed under the terms of the Creative Commons Attribution License (http://creativecommons.org/licenses/by/2.0), which permits unrestricted use, distribution, and reproduction in any medium, provided the original work is properly cited.

\begin{abstract}
Background: Pain and depression are known to be associated in later life, and both have a negative effect on physical performance both separately and in combination. The nature of the relationships between pain intensity and depression in elderly persons experiencing pain is less clear. The objectives of this study were to explore which factors are associated with depressed mood in older people experiencing pain, and to test the hypothesis that older people experiencing pain are at risk of depressed mood according to the severity or frequency of their pain. In addition we explored whether other potentially modifiable factors might increase the risk of depressed mood in these persons.
\end{abstract}

Methods: The study is a secondary analysis of baseline data for four hundred and six communitydwelling non-disabled people aged 65 and over registered with three group practices in suburban London who had experienced pain in the past 4 weeks. Intensity and frequency of pain was measured using 24 item Geriatric Pain Measure (GPM) and the presence of depressive symptoms using the 5 item Mental Health Inventory. Risk for social isolation was measured using the 6 item Lubben Social Network scale and instrumental activities of daily living (IADL) were also measured.

Results: Overall 76 (19\%) had depressed mood. Pain frequency and severity were not statistically significantly associated with depressed mood in this population. In multivariate analyses, significant predictors of the presence of depressive symptoms were difficulties with basic ADLs (OR 2.8, 95\% Cl I.I.7.8), risk for social isolation (OR 4.I, 95\% Cl I.8-9.3), and basic education only (OR 2.2, 95\% Cl I.I-4.4).

Conclusion: Older people experiencing pain are also likely to experience depression. Among those experiencing pain, social network and functional status seem to be more important predictors of depressive symptoms than the severity of pain. Further studies should evaluate whether improvement of social network and functional status might reduce depressive symptoms in older patients. 


\section{Background}

The inter-relatedness of pain and depression can be a clinical challenge resulting in diagnostic and therapeutic uncertainty, and in polypharmacy. A recent survey of nearly 20,000 adults in five European countries found that $28 \%$ of those with one depressive symptom had chronic pain, whilst $43 \%$ of those with major depression reported chronic pain [1]. The Canadian Community Health Survey of 118533 community-dwelling adults found that chronic back pain occurred in $20 \%$ of clinically depressed adults compared with $9 \%$ of the whole population, and that chronic back pain was the strongest predictor of major depression [2]. One view of the relationship between pain and depression is that each can increase the risk of the onset and gravity of the other [3]. An alternative view, supported by empirical evidence from the Baltimore Epidemiological Catchment Area study's data on back pain, is that chronic or repeated episodes of depression doubled the risk of developing pain, but that pain did not increase the risk of depression [4].

Pain and clinical depression are known from other studies to be associated in later life [5], and both have a negative effect on physical performance both separately and in combination [6]. Since the burden of pain-inducing pathologies increases with age, we might expect the relationships between depression and pain to be more obvious in older people. For example, in our community study in London (which had the same study population as reported here) we found that $45 \%$ of women and $34 \%$ of men aged 65 and over reported pain in the previous four weeks, that pain had a profound impact on activities of daily living, and that there was a significant association between the experience of pain and depressed mood [7]. However, most of those with chronic pain did not have depressed mood, and most of those with depressed mood did not report chronic pain. Other factors must be involved in the relationship between pain and depression, and this paper explores these factors.

According to some studies depressed mood is associated with pain experience in men more than in women [8], and is also directly associated with pain severity [9]. Psychological distress (both anxiety and depression symptoms) in older people experiencing pain may be associated with less education, lower incomes, higher consumption of analgesics, and longer duration of pain [10].

Given these associations, we might anticipate that the risk of depressed mood in older people experiencing pain would be associated with the severity or frequency of their pain, their demographic characteristics, and their functional and cognitive losses. This paper explores these relationships through secondary analysis of data from a community sample of patients aged 65 and over recruited through general practice.

Our primary hypothesis was that amongst older people experiencing pain, depressed mood would be associated with pain frequency and severity. In addition, we hypothesised that depressed mood in those experiencing pain may be associated with advancing age, male sex, being at risk of social isolation, limited education, lower income, functional loss, co-morbidities (as reflected by polypharmacy), and memory loss (which can be a feature of both dementia syndromes and depression).

\section{Methods}

Three large group practices in suburban London were recruited to participate in a multi-centre, multi-national randomised controlled trial investigating the effect of the Health Risk Appraisal for Older persons (HRA-O) instrument on health behaviours and status [11]. The focus of the study was the 'well' old population, and it took place between 2000 and 2003. The HRA-O is a multidimensional, self-completion questionnaire that collects information on health, functional status, health behaviours, preventive care and psychosocial factors in older people. The development of the HRA-O questionnaire, the derivation of its component instruments and the feasibility of its use in British primary care have been reported elsewhere $[12,13]$.

Practices were purposively selected for their interest in primary care for older people, location in suburban London and routine use of electronic medical recording systems in clinical encounters. Local research ethics committee approval was obtained from Brent Local Research Ethics Committee (BEC745) and King's College Hospital Research Ethics Committee (protocol 01-010). A full account of the methodology of the study is available elsewhere [14].

To identify eligible patients aged 65 and over, practice lists were reviewed by general practitioners to identify patients who had moved, died or were ineligible for the study. Eligibility criteria were: those living at home, without A) evidence of need for human assistance in basic activities of daily living, B) high dependency due to major physical or psychiatric illness, or cognitive impairment, or C) a terminal illness. Patients also had to have a sufficient level of English to complete the questionnaires. This patient population was further evaluated using the Probability of Recurrent Admissions (Pra) questionnaire [15] and asked to complete a consent form, by post. The Pra measures the risk of hospital admission and stratifies the population by level of risk for future in-patient care, and was used in the main study as the basis for risk-stratified outcome analyses. 
Eligible and consenting patients were posted the HRA-O questionnaire. The HRAO questionnaire contains a number of validated tools, including ones for pain, social network, functional abilities, memory loss and depressed mood. The findings reported in this paper are from the baseline completion of the questionnaire.

Those who gave positive answers to a screening question about the experience of pain in the previous four weeks then completed the Geriatric Pain Measure (GPM), a 24 item multidimensional pain questionnaire that captures information on pain experience (measured on 10 point modified Likert scales) and impact of pain on everyday living [16]. Answers on a scale of 0 to 10 for Pain severity in the last seven days were re-coded to mild (0-3), moderate (4 to 7 ) and severe (8-10). To identify depressed mood we used the 5 item Mental Health Inventory Screening test [17], a tool validated for screening for depressed mood [18] that does not depend on somatic symptoms, and that categorises respondents as having or not having depressed mood.

Social networks were measured using the six item version [19] of the Lubben Social Network Scale [20], developed specifically for use among older adult populations and used widely in both research and clinical settings [21-24]. On the Lubben scale a scale of nought to thirty captures the extent of social contact with family and friends, and being at risk of social isolation is defined as having a score of less than twelve. Functional ability was assessed using a modified version of the Lawton and Brody activities of daily living scale [25] that captures both basic (BADL) and instrumental activities (IADL). Polypharmacy was defined as receiving four or more prescribed medicines on a regular basis, and changes in walking, climbing steps and getting in or out of cars and buses were measured using the Fried questionnaire [26]. Memory problems were captures using a memory self-report instrument [27]. Information about current income and years of education was collected; those finishing education at 14 or less years were categorised as having basic education only. There was no imputation of missing data for any of these characteristics.

Data analysis was carried out among the sub-sample of elderly persons who answered in the affirmative to a screening question on pain in the last four weeks were included in the dataset. Analyses were carried out using the Statistics Package for Social Sciences (SPSS) [28]. The analyses were conducted in the following sequence:

1) Bivariate analysis using chi square was used to compare those with and without depressed mood for pain frequency and severity, age, sex, living alone, limited education, lower income, functional loss, co-morbidities, and memory loss.
2) Factors associated with depressed mood at $p=0.05$ or less were entered in a logistic regression equation with backwards stepwise removal of factors to obtain a parsimonious model. Factors were removed according to their adjusted odds ratio, starting with the least significant associations.

\section{Results}

Four thousand four hundred and sixty six patients aged 65 and over were identified across the three practices, of which 391 were excluded based on a priori criteria, so that a total of 4075 older people were sent an invitation letter and a consent form. Overall 2620 of the 4075 returned a completed questionnaire and consent form (64\%). Based on the questionnaire 117 were excluded because of selfreported need for human assistance in basic activities of daily living, leaving 2503 people in the study.

After randomisation 1240 older people were posted the health risk appraisal questionnaire at baseline, of which 1090 completed and returned the questionnaire, a response rate of $88 \%$. Those who returned a completed health risk appraisal questionnaire were less likely to describe their health as fair or poor rather than excellent, very good or good, than non-responders $(23.1 \%$ vs. $34.7 \% \mathrm{p}=0.002$ ), were on average about one year older than participants, and women tended to refuse more often than men. In other respects responders and nonresponders were similar (Stuck et al 2007).

One thousand and seventeen responders (82\%) completed the screening question on pain experience in the previous four weeks. Four hundred and six (39.9\%) had experienced pain in the past 4 weeks and this group of older people was used for the analysis. Figure 1 shows the derivation of the study sample.

The characteristics of the 406 older people reporting pain in the previous four weeks are shown in table 1 . The study population self-reported ethnic origin, and $98 \%$ described themselves as white; because of this ethnicity has not been included in the analysis of factors associated with pain and depression.

Table 2 shows the factors associated with depressed mood in this sub-population experiencing pain in the last four weeks, both unadjusted and adjusted for other factors. Bivariate analyses suggested that depressed mood was significantly associated with memory problems, taking 4 or more medicines on a regular basis, difficulties with at least one basic and one instrumental activity of daily living, recent reduction in activities, being at risk of social isolation and having had only basic level education. There was no significant association between depressed mood and either the frequency or the severity of pain. 


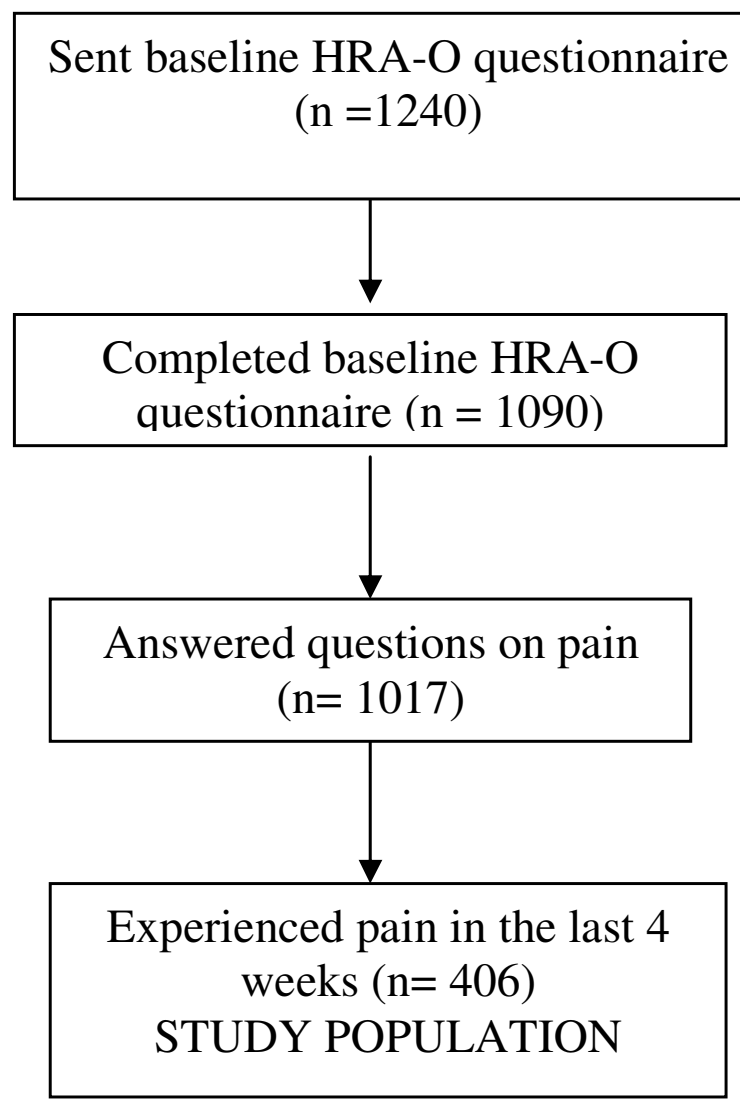

Figure I

Derivation of the study population.

When the significant factors were entered in a stepwise backward regression to obtain the most parsimonious model, three factors remained associated with depressed mood in those experiencing pain. Risk of social isolation and basic level of education remained significant, and difficulty with at least one BADL also had a significant impact on depressed mood. For risk of social isolation the odds ratio was $4.3(95 \%$ CI $1.8-10.4, \mathrm{p}=0.001)$, for basic education only it was $2.2(95 \%$ CI $1.1-4.4, \mathrm{p}=$ 0.03 ) and for difficulties with BADL it was $2.8(\mathrm{OR}, 95 \%$ CI $1.1-7.8, \mathrm{p}=0.05)$,

\section{Discussion}

Depressed mood in older people experiencing pain is not associated with pain frequency or severity but is independently associated with risk of social isolation and having had only basic education. These associations may occur because coping strategies for pain may be less effective for those with weaker social networks or less skill in understanding and managing pain. Attention to social support and pain management skills may be appropriate for clinicians working with older people experiencing
Table I: Characteristics of older people reporting pain in the previous four weeks $(n=406)$

\begin{tabular}{|c|c|c|}
\hline Characteristic & $\mathrm{N}$ & $\%$ \\
\hline Age group: $65-74$ & 218 & 53.7 \\
\hline $75-79$ & 101 & 24.9 \\
\hline $80-84$ & 68 & 16.7 \\
\hline 85 and over & 19 & 4.7 \\
\hline Male & 157 & 38.7 \\
\hline Female & 249 & 61.3 \\
\hline Living alone & 259 & 64.3 \\
\hline At risk of social isolation & 59 & 14.6 \\
\hline Depressed mood & 76 & 18.8 \\
\hline Problems with memory & 40 & 10.1 \\
\hline Polypharmacy & 179 & 44.9 \\
\hline Difficulties with BADL & 24 & 6.0 \\
\hline Difficulties with IADL & 169 & 42.9 \\
\hline Recent change in activities & 262 & 67.2 \\
\hline Recent decrease in activities & 210 & 54.3 \\
\hline Basic education only & 230 & 57.1 \\
\hline Receives only state pension & 125 & 31.2 \\
\hline
\end{tabular}

pain and associated depressed mood. Difficulty with BADL was also significantly associated with depressed mood, but this finding should be treated with caution because of the small numbers with BADL impairment. Our hypotheses that age, gender, low income, co-morbidity, pain frequency and severity and memory loss would be associated with depressed mood in those experiencing pain were not confirmed.

There are a number of methodological limitations, which should be taken into account when interpreting the results of this study. The sample was drawn from three general practices in suburban London, and subject to eligibility criteria and disability screening implemented for recruitment into a trial of health promotion, which may limit the generalisability of the results. Because of the cross-sectional nature of the study it is not possible to disentangle cause and effect. The prevalence of pain identi- 
Table 2: Factors associated with depressed mood in those experiencing pain

\begin{tabular}{|c|c|c|c|c|c|c|c|c|c|c|}
\hline Characteristic & $\begin{array}{l}\mathrm{N} \text { with } \\
\text { depressed } \\
\text { mood }\end{array}$ & $\begin{array}{l}\% \text { with } \\
\text { depressed } \\
\text { mood }\end{array}$ & $\begin{array}{l}\text { Unadjusted } \\
\text { odds ratio }\end{array}$ & $\begin{array}{c}95 \% \\
\text { Confidence } \\
\text { intervals }\end{array}$ & & $\mathrm{P}$ value & $\begin{array}{l}\text { Adjusted } \\
\text { Odds ratio }\end{array}$ & $\begin{array}{c}95 \% \\
\text { Confidence } \\
\text { intervals }\end{array}$ & & $P$ value \\
\hline Male & $25 / 155$ & 16.1 & 1.5 & 0.9 & 2.6 & 0.1 & 1.5 & 0.7 & 2.9 & 0.3 \\
\hline Female & $55 / 243$ & 22.6 & & & & & & & & \\
\hline Aged 65-74 & $4 I / 213$ & 19.2 & I.I & 0.7 & 1.8 & 0.65 & 0.9 & 0.5 & 1.8 & 0.8 \\
\hline $\begin{array}{l}\text { Aged } 75 \text { \& } \\
\text { over }\end{array}$ & $39 / 185$ & 21.1 & & & & & & & & \\
\hline Daily pain & $42 / 156$ & 21.2 & 1.3 & 0.8 & 2.2 & 0.35 & 1.7 & 0.8 & 3.6 & 0.2 \\
\hline Less than daily & $30 / 143$ & 17.3 & & & & & & & & \\
\hline Mild pain & $34 / 206$ & 16.5 & & & & & & & & \\
\hline Moderate pain & $36 / 162$ & 22.2 & 1.6 & 1.1 & 2.3 & 0.06 & 1.0 & 0.55 & 1.5 & 0.7 \\
\hline Severe pain & $9 / 26$ & 34.6 & & & & & & & & \\
\hline $\begin{array}{l}\text { Analgesics at } \\
\text { least } 3 \text { times/ } \\
\text { week }\end{array}$ & $37 / 163$ & 22.7 & 1.3 & 0.8 & 2.2 & 0.3 & 0.6 & 0.3 & 1.3 & 0.2 \\
\hline Living alone & $25 / 139$ & 18.0 & 1.0 & 0.7 & 1.6 & 0.6 & 1.6 & 0.8 & 3.3 & 0.2 \\
\hline $\begin{array}{l}\text { Memory } \\
\text { problems }\end{array}$ & $16 / 40$ & 20.5 & 2.0 & 1.0 & 3.9 & 0.001 & 2.1 & 0.8 & 5.4 & 0.1 \\
\hline Polypharmacy & $42 / 174$ & 24.1 & 1.7 & 1.0 & 2.7 & 0.05 & 1.3 & 0.6 & 2.5 & 0.5 \\
\hline $\begin{array}{l}\text { Difficulties } \\
\text { with BADL }\end{array}$ & $12 / 24$ & 50.0 & 4.4 & 1.9 & 10.3 & $<0.001$ & 2.8 & 1.1 & 7.8 & 0.05 \\
\hline $\begin{array}{l}\text { Difficulties } \\
\text { with IADL }\end{array}$ & $44 / 166$ & 26.5 & 1.9 & 1.2 & 3.1 & 0.01 & 1.0 & 0.5 & 2.2 & 0.9 \\
\hline $\begin{array}{l}\text { Recent change } \\
\text { in activities }\end{array}$ & $59 / 257$ & 23.0 & 1.7 & 0.9 & 3.0 & 0.07 & 1.0 & 0.4 & 2.6 & 0.9 \\
\hline $\begin{array}{l}\text { Recent } \\
\text { decrease in } \\
\text { activities }\end{array}$ & $50 / 207$ & 24.2 & 1.8 & 1.1 & 3.1 & 0.025 & 0.7 & 0.3 & 1.7 & 0.5 \\
\hline $\begin{array}{l}\text { At risk of social } \\
\text { isolation }\end{array}$ & $22 / 58$ & 37.9 & 3.1 & 1.7 & 5.6 & $<0.0001$ & 4.3 & 1.8 & 10.4 & 0.001 \\
\hline $\begin{array}{l}\text { Basic education } \\
\text { only }\end{array}$ & $60 / 227$ & 26.4 & 3.0 & 1.7 & 5.3 & $<0.0001$ & 2.2 & 1.1 & 4.4 & 0.03 \\
\hline $\begin{array}{l}\text { Receives only } \\
\text { state pension }\end{array}$ & $47 / 270$ & 17.4 & 0.6 & 0.4 & 1.1 & 0.09 & 1.5 & 0.7 & 3.0 & 0.30 \\
\hline
\end{tabular}

Unadjusted odds ratios are derived from univariate analyses and adjusted odds ratios are derived from multivariate analyses. 
fied within this sample may be lower than that in the general population of older primary care patients, partly because we deliberately excluded disabled older people and partly because the participants were a self-selecting sub-group who returned lengthy questionnaires. The number of older people with severe pain is small, and a type 2 error is possible. The dataset for analysis was constructed around a screening question about pain in the last four weeks, resulting in a wide variety of pain experiences being incorporated into a single group. We also measured depressed mood (which is a common clinical problem in primary care) rather than major depression, which is less common.

\section{Implications for practice}

Daily pain appears to be prevalent among communitydwelling older people and is often untreated [29]. Chronic pain has a wide-ranging impact on daily life and activities [30], including functional limitations, fatigue, sleeping problems, and depressed mood [5] and significantly reduces quality of life [31]. Given the potential impact of pain, clinicians need to be able to accurately assess and understand the nature of pain in everyday life. Pain and depression appear to be closely connected. For example, several studies report that depression is associated with more pain complaints, greater pain intensity, longer duration of pain and greater likelihood of nonrecovery [32]. Clinicians working with older people who experience persistent pain and who are also depressed need to consider how best to treat each component of their patient's problem. Given the findings from the literature review [32], one plausible way to alleviate depression in older people experiencing pain may be to treat pain aggressively. However, this simple clinical approach may be complicated by other factors mediating between pain and depression. For example, a study of a large cohort of American women aged 55 to 72 showed that absence of a confidant, having few close friends and few relatives was associated with both higher levels of persistent or recurrent bodily pain and depressed mood [33]. Similarly, persistent depressed mood is associated with significant physical impairment [34]. Those considering treatment of depression in older people experiencing pain may need, therefore, to consider the pain itself, the older person's social relationships and their functional impairments, as well as the depression symptoms.

\section{Conclusion}

Given the limitations of this secondary analysis our conclusions are tentative. In our sample older persons experiencing pain were at risk for depression, as we would predict from the literature. However, contrary to other findings, amongst those experiencing pain social network and functional status seem to be more important predictors of depressive symptoms than the severity of pain.
These findings need to be confirmed or refuted in other studies. Further studies should also evaluate whether improvement of social networks or functional status might reduce depressive symptoms as effectively as addressing pain control, in older patients with depressed mood and persistent pain.

\section{Competing interests}

The authors declare that they have no competing interests.

\section{Authors' contributions}

AS, CS, DH \& SI conceived, designed and implemented the study on which this paper is based, analysed and interpreted the results and contributed to the writing of this paper; GG and KK managed the study, entered and cleaned all the data, carried out data analysis, interpreted the results and contributed to the writing of this paper; CC undertook the literature review, carried out secondary data analysis and contributed to the writing of this paper. All authors read and approved the final version of the manuscript.

\section{Acknowledgements}

We thank the practices and patients involved in the study. Funding sources: European Commission project QLK6-CT-1999-02205 and the Federal Education Science Ministry, Berne, Switzerland BBW 9903 I I.I. Neither of these bodies has been involved in study design, in data collection or interpretation, or in manuscript preparation.

\section{References}

I. Ohayon M, Schatzberg A: Using chronic pain to predict depressive morbidity on the general population. Arch Gen Psychiatry 2003, 60:39-47

2. Currie S, Wang J: Chronic back pain and major depression in the general Canadian population. Pain 2004, 1 07:56-60.

3. Lepine J-P, Briley $M$ : The epidemiology of pain in depression. Human Psychopharmacol Clin Exp 2004, I9:S3-S7.

4. Larson S, Clark M, Eaton W: Depressive disorder as a long-term antecedent risk factor for incident back pain: a I 3 year follow up study from the Baltimore Epidemiological Catchment Area sample. Psychol Med 2004, 34:2II-2I9.

5. Jakobsson U, Klevsgard R, Westergren A, Hallberg IR: Old people in pain: A comparative study. J Pain Symptom Manage 2003, 26:625-636.

6. Mossey JM, Gallagher RM, Tirumalasetti F: The effects of pain and depression on physical functioning in elderly residents of a continuing care retirement community. Pain Med 2000, I:340-350.

7. Carmaciu C, lliffe S, Kharicha K, Harari D, Swift C, Gillman G, Stuck AE: Health Risk Appraisal in Older People: 3. The experience, impact and context of pain \& their implications for General Practitioners. Br J Gen Practice 2007, 57:630-635.

8. Bergh I, Steen G, Waern M, Johansson B, Oden A, Sjostrom B, Steen $B$ : Pain and its relation to cognitive function and depressive symptoms: A Swedish population study of 70-year-old men and women. J Pain Symptom Manage 2003, 26:903-912.

9. Turk D, Okifuji A, Scharff L: Chronic pain and depression - role of perceived impact and perceived control in different age cohorts. Pain 1995, 61:93-101.

10. Soares JF, Sundin O, Grossi G: The stress of musculoskeletal pain - a comparison between primary care patients in various ages. J Psychosomatic Research 2004, 56:297-305.

II. Stuck AE, Elkuch P, Dapp U, Anders J, Iliffe S, Swift C, for the Pro-Age pilot study group: Feasibility and yield of a self-administered questionnaire for health risk appraisal in older people in three European countries. Age \& Ageing 2002, 3 I :463-7. 
12. Iliffe S, Kharicha K, Harari D, Swift C, Stuck A: health risk appraisal for older people in general practice using an expert system a pilot study. Health \& Social Care in the Community 2005, I3:21-29.

13. Stuck AE, Kharicha K, Dapp U, Anders J, Wolgang von Renteln Kruse, Meier-Baumgartner H, Harari D, Ivanova K, Bachmann, Egger M, Gilman G, Higa J, Beck J, Swift C, Iliffe S: Development, feasibility and performance of a Health Risk Appraisal questionnaire for older persons. BMC Medical Research Methodology 2007, 7:I.

14. Stuck AE, Kharicha K, Dapp U, Anders J, Wolgang von Renteln Kruse, Meier-Baumgartner H, lliffe S, Harari D, Bachmann, Egger M, Gilman G, Beck J, Swift C: The ProAge study: an international randomised controlled study of Health Risk Appraisal for older persons based in general practice [ISTRCTN28458424]. BMC Medical Research Methodology 2007, 7:2.

15. Pacala JT, Boult C, Boult L: Predictive validity of a questionnaire that identifies older persons at risk for hospital admission. J Am Geriatr Soc 1995, 43:374-7.

16. Ferrell BA, Stein WM, Beck JC: The Geriatric Pain Measure Validity, reliability and factor analysis. J Am Geriatr Soc 2000, 48:1669-1673.

17. Stewart AL, Hays RD, Ware JE: The MOS short-form general health survey Reliability and validity in a patient population. Med Care 1988, 26:724-732.

18. Rumpf H, Meyer C, Hapke U, John U: Screening for mental health: validity of the MHI-5 using DSM-IV axis psychiatric disorders as gold standard. Psych Research 200I, 1 05:243-253.

19. Lubben J, Blozik E, Gillmann G, Iliffe S, von Renteln Kruse W, Beck J, Stuck AE: Performance of an abbreviated version of the Lubben Social Network Scale among three European community-dwelling older adult populations. Gerontologist 2006, 46:503-5I3.

20. Lubben JE, Gironda MW: Social Support Networks. In Comprehensive Geriatric Assessment Edited by: Osterweil D, Brummel-Smith K Beck J. New York: McGraw Hill; 2000:121-137.

21. Martire LM, Schulz R, Mittelmark MB, Newsom JT: Stability and change in older adults' social contact and social support: The Cardiovascular Health Study. If Gerontology 1999, 54:302-3 I I.

22. Steiner A, Raube K, Stuck AE, Aronow HU, Draper D, Rubenstein LZ, Beck J: Measuring Psychosocial Aspects of Well-Being in Older Community Residents: Performance of Four Short Scales. Gerontologist 1996, 36:54-62.

23. Rubinstein RL, Lubben JE, Mintzer JE: Social Isolation and Social Support: An Applied Perspective. J Applied Gerontology 1994 I 3:58-72.

24. Luggen AS, Rini AG: Assessment of Social Networks and Isolation in Community-Based Elderly Men and Women. Geriatric Nursing 1995, 16:179-181.

25. Lawton MP, Brody EM: Assessment of Older People: self maintaining and instrumental activities of daily living. Gerontologist 1969, 9:179-186

26. Fried LP, Bandeen-Roche K, Chaves PH, Johnson BA: Preclinical mobility disability predicts incident mobility disability in older women. J Gerontology 2000, 55:43-52.

27. Riege WH: Self-report and tests of memory aging. Clin Gerontol 1982, I:23-36.

28. SPSS UK, St. Andrew's House, West St., Woking, Surrey GU2 I 6EB [http://www.spss.com/uk/]

29. Landi F, Onder G, Cesari M, Gambassi G, Steel K, Russo A, Lattanzio $\mathrm{F}$, Bernabei R: Pain management in frail, community-living elderly patients. Arch Intern Med 2001, I 6 I:2721-2724.

30. Smith B, Elliott A, Chambers W, Smith W, Hannaford P, Penny K: The impact of chronic pain in the community. Fam Practice 2001, I 8:292-299.

31. Chen J, Devine A, Dick IM, Dhaliwal SS, Prince RL: Prevalence of lower extremity pain and its association with functionality and quality of life in elderly women in Australia. I Rheumatol 2003, 30:2689-2693.

32. Bair MJ, Robinson RL, Katon W, Kroenke K: Depression and pain morbidity: a literature review. Arch Intern Med 2003, 1 63:2433-2445

33. Michael YL, Colditz GA, Coakley E, Kawachi I: Health behaviours, social networks, and healthy aging: Cross sectional evidence from the Nurses' Health Study. Quality of Life Research 1999, 8:71 1-722.

34. Kirby M, Bruce I, Coakley D, Lawlor BA: Dysthmia among the community-dwelling elderly. Int J Ger Psychiatr 1999, I4:440-45.

\section{Pre-publication history}

The pre-publication history for this paper can be accessed here:

http://www.biomedcentral.com/1471-2296/10/54/pre pub
Publish with Biomed Central and every scientist can read your work free of charge

"BioMed Central will be the most significant development for disseminating the results of biomedical research in our lifetime. "

Sir Paul Nurse, Cancer Research UK

Your research papers will be:

- available free of charge to the entire biomedical community

- peer reviewed and published immediately upon acceptance

- cited in PubMed and archived on PubMed Central

- yours - you keep the copyright 